\title{
The impact of the ambient environment and building configuration on occupant productivity in open-plan commercial offices
}

\section{Abstract}

Purpose

This paper sets out to understand the impact of the ambient environment on perceived comfort, health, wellbeing and by extension, productivity in the workplace.

\section{Design/methodology/approach}

The research combined an occupant survey considering satisfaction with the ambient environment, health and wellbeing and workplace behaviour with the monitoring of ambient environmental conditions.

\section{Findings}

The paper demonstrates that the ambient environment can have a significant impact on occupant comfort, health and wellbeing, which in turn has implications for built asset performance. Within the ambient environmental factors considered a hierarchy may exist with noise being of particular importance. Occupant behaviour within the workplace was also found to be influential.

\section{Research limitations}

The research was limited to a single commercial office building and a wider range of case studies would therefore be of benefit. The research was also limited to the summer months.

\section{Practical implications}

The findings show that an active approach to asset management is required, by continuously monitoring internal environment and engaging with occupants. This must carefully consider how ambient environmental factors and workplace behaviour impact upon occupant's comfort, health and wellbeing in order to ensure the performance of the built asset is maximised.

\section{Originality/value}

This paper demonstrates that both occupier's workplace behaviour and ambient environmental conditions can have an impact on occupant comfort, health, wellbeing and productivity. The paper strengthens the case for the active management of the workplace environment through environmental monitoring and behaviour change campaigns supported by corresponding changes to workplace culture.

Keywords: Asset management, behaviour, comfort, health, productivity, wellbeing

Article Classification: Research Paper 


\section{Introduction}

There is a growing body of evidence linking the physical environment (including the ambient environment) to occupant performance (Creagh et al., cited in Madeo \& Schnabel, 2014) which recognises that in the commercial office environment, employee costs significantly exceed energy and maintenance costs (CABE, 2005). In this context thinking must extend beyond regulated energy use and occupants per square metre, and should consider occupant wellbeing in order to deliver healthy, comfortable, efficient and resilient built environments.

Clements-Croome and Kaluarachchi (2000) suggest that occupant performance is dependent on healthy buildings, in support of this Gensler (2005) adds that a better working environment could increase productivity by $19 \%$. Occupant wellbeing should therefore be of importance to business owners. However, according to Kok (2012) employees interests are not always top of the agenda in the business environment, and organisations often focus on increased performance for lower costs (Van der Voordt, 2004).

Most studies in this field take a cross sectional or comparative office type approach (Bodin Danielsson \& Bodin, 2009; Lee, 2010; Feige et al., 2013; Kim \& de Dear 2013) or focus on specific factors such as natural and artificial lighting, noise, control or the ambient environment (Wyon, 2004; Lee and Brand, 2005; Lan et al., 2011; Haans, 2014; Seddigh et al., 2015; Lamb \& Kwok, 2016. Haynes (2007) argues that behavioural aspects are also of importance but not widely considered, although more recently behaviour change studies in relation to energy savings have become more prevalent (Mulville et al., 2013; Tetlow et al. 2013; Gulbinas \& Taylor, 2014).

This research explores how both the range of both ambient conditions and occupant behaviour, which appears to be less widely considered, within a given office environment impacts on occupants selfreported health, wellbeing and by extension productivity.

The research demonstrates that while ambient environmental conditions are of importance, occupant behaviour can also be influential in terms of health, wellbeing and productivity in the workplace and 
suggests that an active approach to workplace management is required in such environments. This active approach may include both continuous monitoring of ambient conditions and occupant behaviour change campaigns. Such behaviour change campaigns may need to be supported by wider changes to workplace culture in order to maximise productivity.

\section{Literature Review}

There are a wide range of factors that can influence employee performance and productivity in the workplace, including a range of business environment factors (workplace culture, social ambience, industry performance) (Chandrasekar, 2011) and personal or social factors (general health, motivation, personality, age, gender and behaviour) (Haynes 2007, Cubel et al. 2014). Although several of these factors may at first appear to be external to the immediate building it can be argued that the physical building environment, including the ambient environment, has at least some impact. This is supported by a body of evidence linking the physical building environment to productivity (See Clements-Croome, 2015 for a review). In that context the review that follows focused on the physical building environment including ambient environmental factors.

\section{Measurement}

As highlighted by Clements-Coombe (2015) a lack of productivity in the workplace can be equated to many issues such as absenteeism, leaving early, arriving late and taking longer lunch breaks along with a general frustration with the work environment. According to Feige et al., (2013) worker performance can be linked to productivity, but both are rarely measured in the workplace, which can prove especially difficult where there is no universally accepted measure of office productivity (Haynes, 2008a). It is instead suggested that measuring self-reported subjective productivity through questionnaires may be appropriate (Haynes, 2008b; Feige et al., 2013). Measuring productivity gains in an office environment remains difficult and there would appear to be a lack of consensus in the 
literature about the potential magnitude of such gains with, for instance, Clements-Croome (2013) suggesting 4-10\% gains, while Gensler (2005) notes 19\% gains.

Haynes (2007) sets out a theoretical framework for office productivity noting the importance of occupier work patterns and the behavioural environment (how occupants interact with the environment) in addition to the physical environment (office layout and comfort, including the ambient environment) which is more regularly considered. Building upon this, it is suggested (Haynes, 2007) that the behavioural environment (framed as interaction and distraction) may impact more on people's productivity than the physical environment. In this context there is evidence that behaviour change interventions in the workplace can be successfully used to reduce energy use (Mulville et al., 2013), it may be that a similar approach would also be successful in relation to productivity. There is however also evidence that the physical environment (including the ambient environment) has a significant impact on occupant performance (see Clements-Croome, 2015) and arguably the behavioural and physical environments are interlinked.

What is widely accepted is that male and female occupants experience the office environment differently, with differences observed in levels of satisfaction with the ambient environment, stress levels and sick leave rates (Kim et al. 2013; Bodin Danielsson et al., 2014).

\section{Office Layout, Distraction and Control}

Bodin Danielsson and Bodin (2008) define a range of office types from single occupancy to open plan variations. This in turn has allowed for consideration of the impact of office type on occupants to be explored with issues of stress and sickness rates, personal control (Bodin Danielsson, 2010; Pejtersen et al. 2011; Bodin Danielsson et al., 2014) and noise and disturbance (Bodin Danielsson, 2008; Seddigh et al., 2015) being highlighted, with open plan offices often performing poorly. In open plan offices increased stress levels may be related to disturbance and a lack of personal control (Bodin Danielsson, 2010), while sickness rates may also be associated with increased densities being linked to greater risk of infection (Bodin Danielsson et al., 2014). 
There is evidence that, in open plan offices, occupants may be more sensitive to backgrounds noise than would be otherwise expected (Van der Voordt, 2004) and that medium and large open plan offices may be particularly problematic (Bodin Danielsson and Bodin, 2009). Jahncke et al., (2011) found that memory performance declined in high noise environments while impacts on tiredness and motivation were also observed. Although enclosed or small shared offices may offer more benefit in terms of acoustic sensitivity and privacy (Lee, 2010), Van Der Voort (2004) notes that some occupants may respond more positively to the increased stimuli in open plan offices than others. This may suggest a role for consideration of the level of concentration required for the work being undertaken (Seddigh et al., 2014) and supports the suggestion that an active approach to workplace management may be of benefit (Haynes, 2008c).

Bodin Danielsson and Bodin (2009) note that personal control is a fundamental feature of human behaviour and that it is strongly related to environmental satisfaction. In support of this, Lee and Brand (2005) found a positive correlation between perceived personal control and self-reported job satisfaction. In open plan offices this presents a particular challenge for Facilities Managers and perhaps supports the argument for enhanced user control which, as noted by O'Neill (2008a), can improve employee performance and can be further enhanced by training.

Open-plan offices may also offer benefits. The more flexible arrangements contribute to sustainability by offering energy savings, reduced materials and providing adaptability (Van der Voordt, 2004), thus reducing the cost of change ( $\left.\mathrm{O}^{\prime} \mathrm{Neill}, 2008 \mathrm{~b}\right)$. In addition open plan situations may aid interaction, although the benefits in comparison to other office types have been called into question (Lee, 2010). Veitch et al., (2007) found that those open plan office workers who were more satisfied with their work environment where also satisfied with their jobs, suggesting a role for the physical environment (including ambient environmental factors) in wellbeing and productivity. In addition, O'Neill (2008a) suggests that greater control through the provision of adjustable workspaces may aid satisfaction. It 
may be therefore, through careful design, that the benefits of open plan environments can be maintained (Kim and De Dear, 2013).

The Ambient Environment

It has been suggested that the move over the last 50 years towards air conditioned buildings coupled with the more recent energy efficiency drive has helped create the conditions for sick building syndrome and that in turn this may have had a direct impact on occupant productivity (Smith and Pitt, 2011). Clements-Croome (2013) highlights that the most frequent complaints in office environments relate to thermal comfort and air quality (in addition to overcrowding) and notes that improvements in environmental conditions could result in a $4-10 \%$ increase in productivity. Pejtersen (2006) notes that occupants in open-plan offices are more likely to perceive poor air quality, thermal discomfort and noise (and experience associated wellbeing issues) than occupants of more enclosed spaces. However, Bodin Danielsson and Bodin (2009) found no significant difference in complaints about the ambient environment (when noise was excluded) between office types, and low overall levels of selfreported dissatisfaction with the ambient environment in comparison to issues of noise and privacy. This perhaps supports the view of Haynes (2007) who suggests the behavioural environment to be of particular importance. However, it can be argued that noise and distraction are influenced by layout, configuration and the ambient environment. The importance of the relevant factors may vary with the type of work undertaken with, for instance, comfort being found to be of most importance to 'group' and 'individual process workers' (as defined by Laing et al. cited in Haynes 2008a). What is clear is that health, wellbeing and productivity in the office environment is complex. Contributing to this complexity it has been suggested that one environmental factor may have a mediating effect on another (Bodin Danielsson and Bodin, 2009).

Indoor Air Quality (IAQ) has been shown to have a significant impact on occupant health, wellbeing and productivity (Dorgan and Dorgan, 2005, World Green Building Council 2014) which in turn could impact on absenteeism (Bodin Danielsson et al., 2014). Clements-Croome (2015) notes the 
importance of ventilation, comparing it to the human need for water and highlights the interrelationship between ventilation rate, temperature and humidity noting that increasing levels of ventilation are required in order to maintain feelings of 'freshness' as temperatures increases (Clements-Croome, 2015). This is of particular importance in the context of the predicted impacts of climate change on the built environment (Jones et al., 2013), where for instance, commercial buildings in the UK and particularly in the South-East are expected to become increasingly cooling dominated (Jenkins et al., 2009).

While Bodin Danielsson and Bodin (2009) did not find significant differences between office types in terms of ambient environment complaints, the highest level of complaints in medium sized open-plan offices were in relation to artificial lighting conditions. This may be due to occupants being conscious that they may be sitting further away from a window and therefore natural daylight. Goodrich (cited in Smith and Pitt, 2011) notes that windows and views are psychologically important to workers, offering a chance to refocus while reducing fatigue and stress. Furthermore, Haans (2014) states that the preference for natural lighting, which builds on the human preference for natural products, can have additional health benefits which although not fully understood, must be considered when focusing on occupant productivity. This is supported by Yildirim et al., (2007) who found that visual access to a window positively affects employee satisfaction. However, providing views out must be carefully balanced with the potential impacts of high levels of glazing on overheating and glare (Hee et al., 2015).

\section{Methodology}

As noted by Feige et al. (2013) measuring performance and productivity in the commercial office environment can be challenging and often indirect measures such as absenteeism, staff turnover etc. may be used, alternatively self-reported productivity (occupant survey) may be employed. This research aims to understand the impact of the ambient environment on perceived comfort, health, wellbeing and by extension productivity in an example of the modern office environment while also 
exploring the potential impact of occupant workplace behaviour on those factors. The research uses a self-reported (occupant survey) technique, supported by the monitoring of ambient environmental factors.

Four zones on each of three floors of the building were identified, although three were excluded as they were in alternative use, leaving nine zones in total. The zoning was reflected in the monitoring of ambient environmental conditions and zones were also identified within the occupant survey. The zones on each floor corresponded to quadrants of the floor plan (Zone 1 = South-West, 2 = South-East, $3=$ North-East, $4=$ North-West). Each zone had approximately 30 workstations and there were no physical barriers between the zones. This approach allowed for consideration of the impact of local variations within the building to be taken into account.

A physical survey based on a visual inspection was carried out in addition to the monitoring of temperature, $\mathrm{CO}_{2}$, humidity and noise levels, thus allowing for comparison back to accepted benchmarks and occupants experiences. Readings were taken throughout the zones and daily figures calculated to mitigate the effects of any erroneous readings due to other factors. Continuous monitoring over a five week period provided a detailed insight into the ambient environment. It was not possible to monitor $\mathrm{CO} 2$ in each zone, however manual readings were taken to confirm an even distribution across floors, before one $\mathrm{CO}_{2}$ logger was placed on each floor. Temperature, humidity and $\mathrm{CO} 2$ readings were recorded at ten minute intervals and sound level readings were taken at ten second intervals (shorter intervals would have been of benefit in increasing accuracy, but was not possible with the equipment in use) but over a shorter overall period (one week) and then converted into equivalent continuous noise levels (dBA Leq(h8)) for working hours. The direct measurement of daylight levels was not possible, and self-reported satisfaction was relied upon instead.

The environmental monitoring was supported by a corresponding survey of the occupant's workplace satisfaction. This survey was carried out anonymously using a targeted sampling technique and ninety five members of staff responded, giving a response rate of $33.9 \%$. As the response rate is subject to some sample limitations which make generalisation difficult, a higher response rate would be 
beneficial. The survey was designed and administered online and participants were informed and invited to participate by e-mail. According to Evans and Mathur (2005), online surveys allow for question diversity, controlled sampling and often result in a faster, more efficient process. Moreover, it allows the methodology to be easily repeated in large scale studies. The questions addressed a range of influences directly related to the ambient environment such as air quality, temperature, humidity, noise and lighting. In addition, more general questions related to occupant behaviour, health and wellbeing at work were assessed along with nominal data such as gender, location and proximity to windows. Occupants were given a series of statements and asked to respond on a five-point Likert Scale with space provided for additional comments.

The research approach allowed for the impact on occupants comfort, health and wellbeing associated with local variations such as layout, proximity to windows and the ambient environment, to be further explored. The research was conducted during the summer months only which may influence the overall results and must be considered a limitation. It is therefore suggested that repeating this approach quarterly would be beneficial.

\section{Building Description}

The building used in this study is a three storey commercial office located on the outskirts of the Greater London area, South-East England. The building has a glazing ratio of approximately $85 \%$ and features shading to three facades. The building is square in plan, with $50-75 \%$ of each floor plate given over to open-plan office space and these spaces can be categorised as large open-plan offices (greater than twenty four occupants) as defined by Bodin Danielsson and Bodin (2008). The open-plan spaces feature half-height partitions between individual workstations $(1 \mathrm{~m})$ and these areas have an occupancy density of $8.9 \mathrm{~m}^{2}$ Net Internal Area (NIA) per workspace. This density is higher than the British Council of Offices (BCO) (2013) occupier density survey, which found an average density of $10.9 m^{2}$ NIA per workplace. However, $38 \%$ of the workplaces considered in that study fell within the 8$10 \mathrm{~m}^{2}$ range, so the case considered here can be said to be representative. The occupants participating 
can be considered to be a combination of 'individual' and 'group process workers' as defined by Laing et al. (cited in Haynes, 2008b). As detailed in the results section the ambient environmental conditions in the building are generally within accepted parameters when measured against common standards so it can be argued that the building environment is, to an extent, representative of the wider stock.

\section{Approach to Analysis}

Descriptive statistics (mean and standard deviation) were used to understand the measured environmental data (temperature, humidity, $\mathrm{CO}_{2}$ and noise) and to explore the Likert Type data (mean, mode, median) gained from the occupant surveys. The ordinal data created from the occupant surveys was further analysed using Spearman Rank Correlations for the main self-reported factors (level of satisfaction with environmental conditions, wellbeing, workplace patterns). This helped to explain, for example, the relationship between, dissatisfaction with noise and frequency of headaches. Furthermore Chi-Squared tests were used to understand how nominal factors (gender, location etc.) impact upon the findings of the Likert Type data gathered.

\section{Results}

\section{Environmental Conditions}

For the temperature and humidity parameters there was little measured difference between zones. When all floors were considered together, the first floor (mean $=24.2^{\circ} \mathrm{C}, \mathrm{SD}=0.09^{\circ} \mathrm{C}$ ) was found to be warmer than the ground $\left(\right.$ mean $=23.85^{\circ} \mathrm{C}, \mathrm{SD}=0.28^{\circ} \mathrm{C}$ ) and second floor (mean $=23.66^{\circ} \mathrm{C}, \mathrm{SD}=0.09$ $\left.{ }^{\circ} \mathrm{C}\right)$. The overall temperature profile is generally below the Chartered Institution of Building Services Engineers (CIBSE) benchmark overheating criteria of $25^{\circ} \mathrm{C}$ (CIBSE, 2005). The corresponding humidity data also shows consistency between zones and lower overall humidity on the first floor. Measured humidity in all zones was predominantly in the $40-50 \%$ range, which is within the recommended range of $40-60 \%$ for health and comfort noted by CIBSE (2015). CO2 levels were measured by floor and not zone, the ground floor (mean 546 parts per million (ppm), SD 30ppm) was generally within the Indoor 
Air Quality (IDA) 2 classification of medium quality (400-600 CO2 ppm) as classified by the European Committee for Standardisation (CEN) (2007) and the first floor (mean 655ppm, SD 46ppm = IDA3) was slightly over this level (taken as a mean during occupied hours). The second floor however was closer to and often in the IDA4 (low quality) category (mean 970ppm, SD 76ppm). In relation to the acoustic environment, again there is little difference in performance between zones, however there is a noticeable increase in background noise level when moving from the second floor (53.87dBA Leq $(\mathrm{h} 8)$ ) to the ground floor (57.98dBA Leq(h8)).

\section{Survey Results}

Findings of the occupant survey are presented in Figure 1, for the purpose of clarity in the presentation of these results, where possible, Likert Type items were combined into single Likert Scale items (where four or more similar questions exist). Where factors (such as skin/eye irritation) were found to be of little influence, they have been excluded from the figure.

The Spearman Rank Correlations found that how often occupants take breaks was correlated to how often occupants experienced headaches $\left(r_{s}=.265, p=.010\right)$ indicating more headaches for less breaks, frequency of breaks were also negatively correlated to satisfaction with IAQ $\left(r_{s}=-.232, p=.024\right)$, thermal comfort $\left(r_{s}=-.222, p=.031\right)$ and noise $\left(r_{s}=-.264, p=.010\right)$ with lower satisfaction corresponding to less breaks. A negative correlation was found between incidents of headache and the perceived impact of the work place on productivity $\left(r_{s}=-.328, p=.001\right)$ with those experiencing more headaches perceiving a greater workplace impact. In addition, incidents of headaches was also negatively correlated to satisfaction with noise $\left(r_{s}=-.518, p=<.001\right)$ and IAQ $\left(r_{s}=-.474, p=<.001\right)$ with lower satisfaction corresponding to more frequent headaches. The relationships between other wellbeing factors (eye and skin irritation, sore and or dry throat, fatigue) and overall comfort and the impact of the building on productivity were found not to be significant. Finally, analysis also found a negative correlation between the importance of access to controls and overall perceived comfort levels $\left(r_{s}=-\right.$ 
$.402, p=<0.001)$ indicating those less satisfied with overall comfort believed access to controls to be important.

The Chi-Squared tests found significant relationships existed between gender and problems with IAQ $((1, \mathrm{n}=95)=8.191, \mathrm{p}=.001)$, thermal comfort $((1, \mathrm{n}=95)=8.568, \mathrm{p}=.003)$, room temperature $((1$, $n=95)=9.58, p=.002)$, overall comfort $((1, n=95)=14.452, p<.001)$ and the occurrence of headaches $((1$, $\mathrm{n}=95$ )=11.674, $\mathrm{p}=.001$ ) with females more likely to note more significant issues. The zone that occupants were located in had a significant relationship with thermal comfort $((1, n=95)=13.922$, $p=<.001)$ and although Figure 1 would appear to suggest similar relationships between zone and acoustic satisfaction and incidence of headaches, this was found not to be significant. Further relationships did exist between floor and thermal comfort $((1, n=95)=13.348, p<.001)$, noise $((1$, $\mathrm{n}=95)=4.964, \mathrm{p}=.026)$ and IAQ $((1, \mathrm{n}=95)=5.425, \mathrm{p}=.020)$. The relationship between proximity to window and satisfaction with daylight was found to be significant $((1, n=94)=3.84, p=.05)$ however, the relationship with artificial lighting satisfaction was not. Furthermore, the relationship between proximity to windows perceived comfort and proximity to windows and the perceived impact of the workplace on productivity were found not to be significant. 


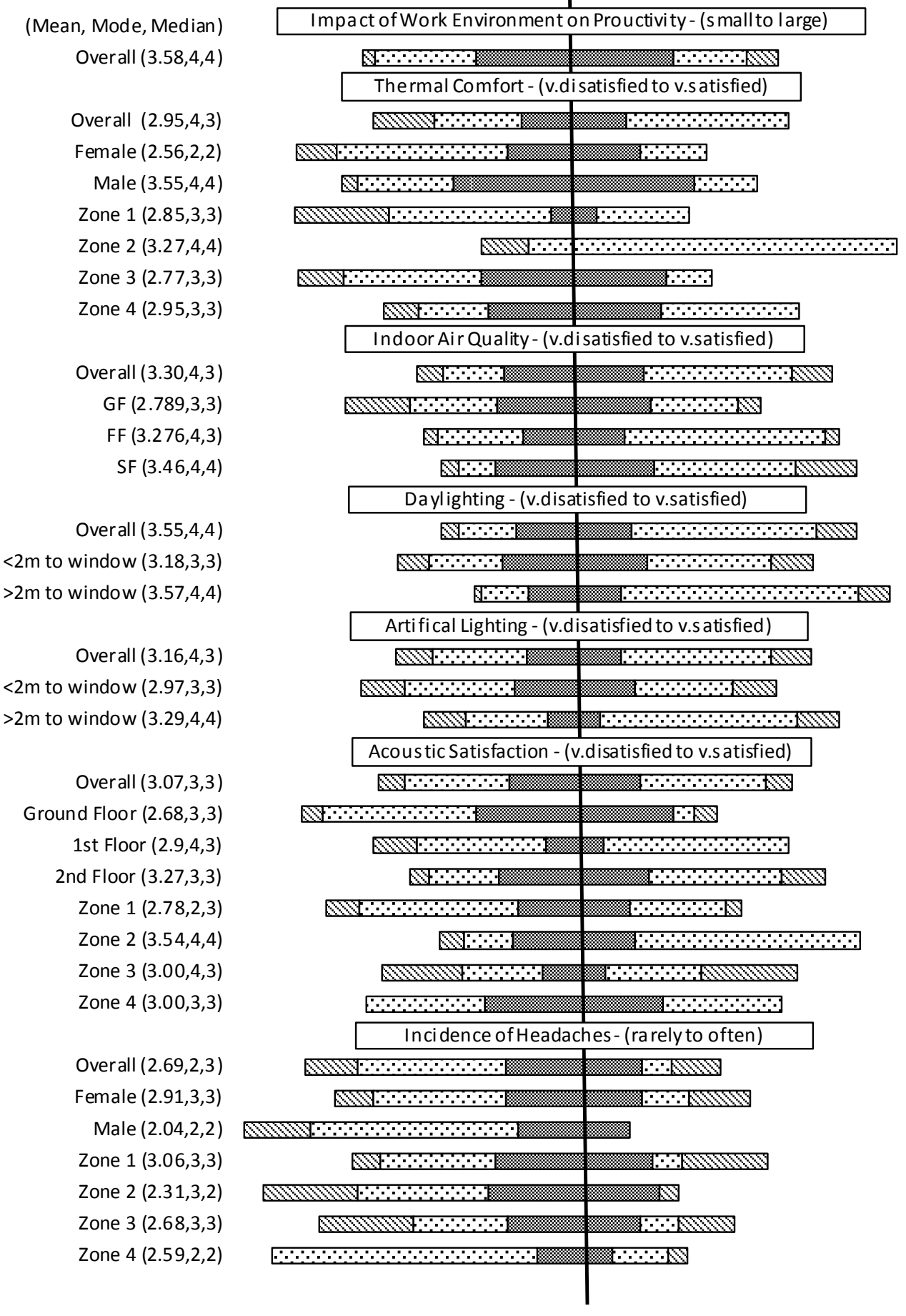

Figure 1: Occupant Survey Results

\section{Discussion}

The research has been able to highlight a number of key issues in relation to occupant health, wellbeing, and by extension, productivity in the commercial office environment. The research 
reinforced the findings of Kim et al., (2013) and others, demonstrating that perceptions of environmental comfort and health can be significantly influenced by gender, with females more sensitive to thermal and acoustic issues. When considered along with the correlation between users who are less satisfied with overall comfort levels and a preference for access to control, this presents a challenge where open-plan offices are common and opportunity for local controls are limited. However, as noted by O'Neill (2008a), the availability of local controls and adjustable features has the potential to help address such issues. Noise and privacy issues may be more challenging to address and presents a particular challenge to designers, asset and Corporate Real Estate (CRE) managers if the benefit of open-plan offices are to be realised.

Interestingly, measured data suggested that the $2^{\text {nd }}$ floor provided the poorest levels of IAQ (mean $\mathrm{CO}_{2}=970 \mathrm{ppm}$ ) with the ground floor offering the highest quality (mean $\left.\mathrm{CO}_{2} \mathrm{ppm}=564 \mathrm{ppm}\right)$ and the findings of the occupant survey found a significant difference in perceived IAQ by floor, however this indicated the ground floor offered the lowest levels of satisfaction (See Figure 1). Conversely the ground floor recorded the highest levels of background noise (57.98dBA Leq(h8)) while the second floor the lowest $(53.87 \mathrm{dBA}$ Leq(h8)). This finding was somewhat unexpected and may suggest that a hierarchy exists between the overall factors that influence environmental comfort, especially where the relative differences are of small magnitude (such as within a single building). In this case (a large open-plan office) the acoustic environment would appear to have a larger impact. This is supported by Bodin Danielsson and Bodin (2009) who found that when noise was excluded there was no significant difference in levels of complaints about the ambient environment between office types and also suggested that one environmental factor may have a mediating effect on another. This is perhaps further supported by the correlation found between those less satisfied with the acoustic environment and a greater frequency of headaches, with those experiencing more frequent headaches also believing the workplace had a greater impact on their productivity. Although it should be noted that perceived IAQ was also correlated to incidents of headaches. The presence of such a hierarchy, which 
arguably may change by season, would require the asset manager to engage in continuous monitoring of the space (beyond reactions to complaints) to maximise productivity.

In addition to differences between floors, a significant difference between zones in relation to perceived thermal comfort was identified (see Figure 1) with those in zone 2 (South-East) more satisfied. This difference was noted despite little measured variation between environmental conditions across zones. For example, maximum measured difference between mean temperatures (during occupied hours) across all zones was $+/-0.72^{\circ} \mathrm{C}$ (zone $1-2$ ). At the same time no significant relationship was found between zones and acoustic satisfaction or incidents of headaches and the immediate reason for the variation in perceived thermal comfort between zones is unclear.

In the case of this research proximity to windows (and therefore access to views and daylight) was not found to be a significant influencing factor on overall comfort or the perceived impact of the workplace on productivity. Although it did not appear to influence overall workplace satisfaction there was a relationship with daylight satisfaction, this perhaps supports the idea of a hierarchy of importance in terms of ambient environmental conditions.

In addition to the issues of location, the study found occupants workplace behaviour to be a significant factor in terms of health and wellbeing, with evidence that those who take breaks more often being less likely to experience headaches and less likely to be dissatisfied with IAQ, thermal comfort and noise. This can be linked back to Haynes (2007) who suggests the behavioural environment to be of particular importance. Changes in behaviour may therefore change the perception of environmental conditions. This could be as a result of breaks increasing wellbeing, or it could be also related to increased casual interaction which as noted by Haynes (2007) can be of benefit to productivity. In this context, in addition to active monitoring of ambient environmental conditions it may also be necessary for CRE managers to engage in occupant behaviour change campaigns (for instance in relation to the frequency of breaks) to improve overall health and wellbeing and in turn maximise productivity. This active approach builds upon the suggestion of Haynes (2008c) that an active approach to workplace management to support both the organisation and the individual may be of 
benefit. Changing the behaviour of occupants in the workplace can however be difficult (Maréchal, 2010) and a change in workplace culture may be necessary (Chandrasekar, 2011) to achieve a positive outcome. This presents a challenge to CRE managers. There is however evidence that such behaviour change campaigns can be successful in other contexts (Mulville et al., 2013).

\section{Conclusion}

This research aimed to understand how a range of ambient environmental conditions and occupant behaviour may impact upon perceptions of comfort, health, wellbeing and ultimately productivity in the workplace.

The research demonstrates that significant differences can exist in relation to comfort, health, wellbeing and by extension productivity within individual buildings, and that this may not always be reflected in measurable differences in directly related ambient conditions. This suggests that, within the generally accepted comfort ranges, there may be a hierarchy of the influence of environmental factors, with noise levels of particular importance. Gender factors and access to controls present further challenges in providing productive workspaces in open plan configurations, where desk level control (of local conditions) may be of benefit. Furthermore, occupant workplace behaviour was found to be a significant factor in perceived environmental comfort and wellbeing. It may be that changes in occupant behaviour, in this case frequency of breaks, can improve perceived environmental satisfaction.

From the CRE management perspective the research highlights the importance of an active approach to management of the workplace environment. This could include both continuous environmental monitoring and behaviour change campaigns.

Further research would be of benefit in relation to the potential for occupant behaviour change interventions to help improve occupant wellbeing. Greater consideration of occupant satisfaction in the workplace has the potential to contribute to the delivery of a sustainable built environment. This 
has benefits at societal level by improving health (and reducing health care costs) and increasing productivity and output, thus having a positive impact on the wider economy.

\section{References}

Bodin Danielsson, C. \& Bodin, L. (2008), "Office-type in relation to health, well-being and jobsatisfaction among employees", Environment \& Behaviour, Vol. 40, pp.636-668

Bodin Danielsson, C. \& Bodin, L. (2009), "Difference in satisfaction with office environment among employees in different office types", Journal of Architectural Planning and Research, Vol. 26, pp.241257.

Bodin Danielsson, C., Chungkham, H.S., Wulff, C. \& Westerlund, H. (2014), "Office design's impact on sick leave rates", Ergonomics, Vol. 57, pp.139-147

Bodin Danielsson, C. (2010), "Office design's influence on employees' stress levels", available at: http://www.aia.org/aiaucmp/groups/aia/documents/pdf/aiab087211.pdf

British Council of Offices (2013), "Occupier Density Study 2013", available at: http://www.architectsjournal.co.uk/Journals/2013/09/10/c/y/n/BCO-Occupier-Density-Study--Final-report-2013.pdf (accessed 24 October 2015).

CABE (2005), "The Impact of Office Design on Business Performance", available at: http://webarchive.nationalarchives.gov.uk/20110118095356/http:/www.cabe.org.uk/files/impac t-office-design-full-research.pdf (accessed 20 October 2015).

Chandrasekar, K. (2011), "Workplace environment and its impact on organisational performance in public sector organisations", available at: http://www.ijecbs.com/January2011/N4Jan2011.pdf (accessed 15 October 2015).

CIBSE (2015), "Guide A: Environmental Design", Chartered Institution of Building Services Engineers, London.

CIBSE (2005), "TM36 Climate Change and the Indoor Environment: Impact and Adaptations", Chartered Institution of Building Services Engineers, London.

Clements-Croome, D. (Ed.) (2013), “Creating the Productive Workplace”, Routledge, Oxon, UK.

Clements-Croome, D. (2015), "Creative and Productive workplaces: A Review", Intelligent Buildings International, Vol. 7 No. 4, pp.164-183

Clements-Croome, D. \& Kaluarachchi, Y. (2000), "Assessment and measurement of productivity", in Clements-Croome, D. (Ed.), Creating the Productive Workplace, Routledge, Oxon, UK.

Cubel, M., Nuevo-Chiquero, A., Sanchez-Pages, S. and Vidal-Fernandez, M. (2014), “Do Personality Traits Affect Productivity?", available at: http://ftp.iza.org/dp8308.pdf (accessed October 09, 2015).

Dorgan, C.E. \& Dorgan, C.B. (2005), "Assessment of link between productivity and indoor air quality", in Clements-Croome, D. (Ed.), Creating the Productive Workplace (2013), Routledge, Oxon, UK. 
European Committee for Standardisation (2007), "EN 13799: Ventilation for non-residential buildings - Performance requirements for ventilation and room conditioning systems", European Centre for Standardization, Brussels.

Evans, J.R. \& Mathur, A., (2005), "The value of online surveys", Internet Research, Vol. 15 No. 2, pp.195-219.

Feige, A., Wallbuam, H., Janser, M. \& Windlinger, L. (2013), "Impacts of sustainable office buildings on occupants comfort and productivity", Journal of Corporate Real Estate, Vol. 15, pp. 7-34.

Fisk, W.J. (1999). "Estimates of potential nationwide productivity and health benefits from better indoor environments: An update", In Spengler, J.D., Samet, J.M. and McCarthy, J.F. (Eds.), Indoor air quality handbook, McGraw-Hill, New York.

Gensler (2005), "These four walls: the real British office", Gensler, London.

Gulbinas, R \& Taylor, J. (2014), "Effects of real-time eco-feedback and organizational network dynamics on energy efficient behaviour in commercial buildings", Energy and Buildings, Vol. 84, pp. 493-500. doi:10.1016/i.enbuild.2014.08.017

Haans, A. (2014), "The natural preference in people's appraisal of light" Journal of Environmental Psychology, Vol. 39, pp.51-61.

Haynes, B. (2007), "Office productivity: a theoretical framework", Journal of Corporate Real Estate, Vol.9, pp.97-110.

Haynes, B. (2008a), "An evaluation of the impact of the office environment on productivity", Facilities, Vol. 6, pp.178-195

Haynes, B. (2008b), "The impact of office comfort on productivity", Journal of Facilities Management, Vol. 6, pp.37-51.

Haynes, B. (2008c), "The impact of office layout on productivity", Journal of Facilities Management, Vol. 6, pp.189-201.

Hee, W.J., Alghoul, M.A., Bakhtyar, B., OmKalthum, E., Shameri, M.A., Alrubaih, M.S. \& Sopain, K. (2015), "The role of window glazing on daylighting and energy saving in buildings", Renewable and Sustainable Energy Reviews, Vol. 42, pp.323-343.

Jahncke, H., Hygge, S, Halin, N., Green, A.M. \& Dimberg, K. (2011), “Open-plan office noise: Cognitive performance and restoration", Journal of Environmental Psychology, Vol. 31, pp.373-382.

Jenkins, D. P., Singh, H., \& Eames, P. C. (2009), "Interventions for large-scale carbon emission reduction in future UK offices", Energy and Buildings, Vol. 41, pp.1374-1380.

Jones, K., Mulville, M. \& Brookes, A. (2013), "FM, Risk and Climate Change Adaptation", in Alexander, K., International Journal of Facilities Management proceedings of the $12^{\text {th }}$ EuroFM Research Symposium, 22-24 May, 2013, Prague, Czech Republic. 
Kim, J., de Dear, R., Cândido, C., Zhang, H. \& Arens, E. (2013), “Gender differences in office occupant perception of indoor environmental quality (IEQ)", Building and Environment, Vol. 70, pp.245-256.

Kim, J. \& de Dear, R. (2013), "Workspace satisfaction: The privacy-communication trade-off in openplan offices", Journal of Environmental Psychology Vol. 36, pp.18-26.

Kok, N. (2012), "What's next in real estate? Reintegrating the value chain", available at: http://nilskok.typepad.com/nils-kok/2012/04/whats-next-in-real-estate-reintegrating-the-valuechain.html (accessed 10 October, 2015).

Lamb, S. \& Kwok, K.C.S. (2016). "A longitudinal investigation of work environment stressors on the performance and wellbeing of office workers", Applied Ergonomics, Vol. 52, pp104-111.

Lan, L., Wargock, P. \& Lian, Z. (2011), "Quantitative measurement of productivity loss due to thermal discomfort", Energy and Buildings, Vol. 43, pp.1057-1062.

Lee, S.Y. and Brand, J.L. (2005), "Effects of control over office workspace on perceptions of the work environment and work outcomes", Journal of Environmental Psychology, Vol. 25, pp.323-333.

Lee, S.Y. (2010), "Office layout affecting privacy, interaction, and acoustic quality in LEED-certified buildings", Building and Environment, Vol. 45, pp.1594-1600.

Madeo, F. \& Schnabel, M.A. (Eds.) proceedings of the 48th International Conference of the Architectural Science Association 2014, The Architectural Science Association \& Genova University Press, Genoa Italy, pp. 239-250.

Maréchal, K. (2010). "Not irrational but habitual: The importance of "behavioural lock-in" in energy consumption", Ecological Economics, Vol.69, pp.1104-1114.

Mulville, M., Jones, K. \& Huebner, G. (2013), "The potential for energy reduction in UK commercial offices through effective management and behaviour change", Journal of Architectural Engineering and Design Management, Vol. 10, pp.79-90.

O'Neill, M. (2008a), "A model of environmental control and effective work", Facilities, Vol. 28, pp.118-136.

O’Neill, M. (2008b), "Open plan and enclosed private offices. Research review and recommendations" available at: https://www.knoll.com/media/878/738/OpenClosed Offices wp.pdf

Pejtersen, J., Allermann, L., Kristensen, T.S. \& Poulsen, O.M. (2006), "Indoor climate, psychosocial work environment and symptoms in open-plan offices", Indoor Air, Vol. 16, pp.392-401.

Pejtersen, J., Feveile, H., Christensen, K. \& Burr, H. (2011), "Sickness absence associated with shared open-plan offices - a national cross sectional questionnaire survey", Scandinavian Journal of work, Environment \& Health, Vol. 37, pp.376-382.

Roelofsen, P., (2002), "The impact of office environments on employee performance: The design of the workplace as a strategy for productivity enhancement", Journal of Facilities Management, Vol. 1 No.3, pp.247-264. 
Seddigh, A., Bernston, E., Jönsson, F., Bodin Danielson, C. \& Westerlund, H. (2014), “Concentration requirements modify the effect of office type on indicators of health and performance", Journal of Environmental Psychology' Vol. 38, pp.167-174.

Seddigh, A., Bernston, E., Jönsson, F., Bodin Danielson, C. \& Westerlund, H. (2015), "The effect of noise absorption variation in open-plan offices: A field study with a cross-over design", Journal of Environmental Psychology, Vol. 44, pp.34-44.

Smith, A. and Pitt, M. (2011), "Sustainable workplaces and building user comfort and satisfaction", Journal of Corporate Real Estate, Vol. 13 No. 3, pp. 144-156.

Tetlow, R.M., Beaman, C.P., Elmualim, A.A \& Couling, K. (2013), “Targeting automatic behaviour to reduce small power electricity consumption in office buildings", Paper presented at the 4th Annual TSBE Eng. D. Conference, Reading, UK.

Van der Voordt, T.J.M. (2004), "Productivity and employee satisfaction in flexible workplaces", Journal of Corporate Real Estate, Vol. 6 No.2, pp.133-148.

Veitch, J.A., Charles, K.E., Farley, K.M.J \& Newsham, G.R. (2007), "A model of satisfaction with openplan office conditions: COPE field findings", Journal of Environmental Psychology, Vol. 27, pp.177189.

World Green Building Council. (2014), "Health, wellbeing and productivity. The next chapter for green building", available at: http://www.worldgbc.org/activities/health-wellbeing-productivityoffices (accessed 10 October, 2015).

Wyon, D.P. (2004), "The effects of indoor air quality on performance and productivity", Indoor Air, Vol. 14, pp.92-101.

Yildirim, K., Akalin-Baskaya, A. \& Celebi, M. (2007), "The effects of widow proximity, partition height, and gender on perceptions in open-plan offices", Journal of Environmental Psychology, Vol. 27, pp.154-165. 